\title{
A Study of Early Neonatal Deaths at Kathmandu Medical College Teaching Hospital
}

\author{
Shrestha $\mathrm{M}^{1}$, Bajracharya $\mathrm{BL}^{2}$, Manandhar $\mathrm{DS}^{3}$ \\ ${ }^{1}$ Dr. M Shrestha, MBBS. Medical Officer, ${ }^{2}$ Dr. BL Bajracharya, DCH, Consultant Paediatrician, ${ }^{3}$ Dr. DS Manandhar, Ch. MRCP \\ Prof and HOD Department of Pediatrics, Kathmandu Medical College Teaching Hospital, Sinamangal, Kathmandu, Nepal.
}

Address for Correspondence: Dr. Mahesh Shrestha,

E-mail: sthamahesh@hotmail.com

\begin{abstract}
Introduction: Over 9 million deaths occur each year in the perinatal and neonatal periods globally. 98\% of these deaths take place in the developing world. Nepal has a high neonatal mortality rate (NMR) of 38.6 per 1000 live births (2001). Two thirds of the newborn deaths usually occur in the first week of life (early neonatal death). Newborn survival has become an important issue to improve the overall health status and for achieving the millennium developmental goals of a developing country like Nepal. Aims and Objectives: This study was carried out to determine the causes of early neonatal deaths (ENND) at KMCTH in the two-year period from November 2003 to October2005 (Kartik 2060 B.S. to Ashoj 2062). Methodology: This is a prospective study of all the early neonatal deaths in KMCTH during the two-year study period. Details of each early neonatal death were filled in the standard perinatal death audit forms of the Department. Results: Out of the 1517 total births in the two-year period, there were 10 early neonatal deaths (ENND). Early neonatal death rate during the study period was 6.7 per 1000 live births and early neonatal death rate (excluding less than $1 \mathrm{~kg}$ ) was 6.1 per 1000 live births The important causes of early neonatal deaths were extreme prematurity, birth asphyxia, congenital anomalies and septicaemia. During the study period, there was no survival of babies with a birth weight of less than $1 \mathrm{~kg}$. Among the maternal characteristics, $80 \%$ of the mothers of early neonatal deaths were aged between $20-35$ years. $50 \%$ of the mothers were primigravida. 50\% of the mothers of ENNDs had delivered their babies by caesarean section. Discussion: Most of the early neonatal deaths were due to extreme prematurity. Birth asphyxia was the second most important cause of early neonatal deaths. 70\% of ENNDs were among LBW babies. Prevention of premature delivery, proper management of very low birth weight babies and early detection and appropriate management of perinatal hypoxia have become important interventional strategies in reducing early neonatal deaths in KMCTH. Conclusion: Early neonatal mortality at KMCTH is fairly low. Good care during pregnancy, labour and after the birth of the baby has helped to achieve these results. Low cost locally made equipments were used to manage the sick newborns. Reduction of early neonatal deaths require more intensive care including use of ventilators, surfactant and parenteral nutrition and prevention of preterm births
\end{abstract}

Key words: Early neonatal death (ENND), neonatal mortality

\section{Introduction}

WHO estimates that globally four million still births and four million neonatal deaths occur each year ${ }^{1}$. Out of the 4 million newborns that die each year, 1.5 million newborn deaths occur in the 4 countries of South Asia including $\mathrm{Nepal}^{2}$. Nepal has a high neonatal mortality rate (NMR) of 38.6 per 1000 live births and infant mortality rate (IMR) of 64.2 per 1000 live births in 2001. Although NMR has fallen from 54.2 per 1000 live births in 1991 but the share of NMR in IMR has increased from 40 to $60 \%$ in the same period $^{3}$. It has been estimated that around 30000 neonatal deaths occur in Nepal out of which two thirds of the newborn deaths usually occur in the first week of life. The present high NMR and its major contribution to IMR illustrate the poor status of neonatal health in Nepal. Since the share of NMR in IMR is increasing with each passing year, importance of interventions in improving newborn health is felt at a national and global scale. A study of neonatal deaths would help in finding appropriate strategies to reduce the present high neonatal mortality in the country.

\section{Aims and Objectives of the Study}

This study was carried out to determine the causes of early neonatal deaths (ENND) at KMCTH in the two-year period from November 2003 to October2005 (Kartik 2060 B.S. to Ashoj 2062).

\section{Methodology}

This is a prospective study of all the early neonatal deaths in KMCTH at Sinamangal, Kathmandu during the two year period from November 2003 to October 2005. Each neonatal death is discussed in detail in the Department of Pediatrics within 24-48 hours of death so as to identify any preventable factor. Details of each early neonatal death were filled in the standard perinatal death audit forms of the Department of Pediatrics, KMCTH. Early neonatal deaths were analyzed according to maternal characteristics like maternal age, parity, type of delivery and fetal characteristics like sex, birth weight, and gestational age. Early neonatal deaths were then classified according to Wiggleworth's classification. 
In the hospital, partograph was used during labour and medical personnel both from Department of Pediatrics and Obstetrics attended each delivery. All the newborns including high risk neonates were managed using the locally made low cost equipments like "DSM" Resuscitaire, Phototherapy unit, Warm cot and oxygen hood in the Special care Baby Unit (SCBU).

\section{Results}

Out of the 1517 total births in the two year period, there were 10 early neonatal deaths (ENND). Out of 10 ENND, one was of less than $1 \mathrm{~kg}$ in weight. Early neonatal death rate during the study period was 6.7 per 1000 live births and early neonatal death rate (excluding less than $1 \mathrm{~kg}$ ) was 6.1 per 1000 live births (Table 1). The perinatal mortality rate was 19.1 per 1000 live births and extended perinatal mortality rate was 21.1 per 1000 live births in the study period. The important causes of ENNDs were extreme prematurity, birth asphyxia, congenital anomalies and septicaemia (Fig 2). There were equal numbers of male and female babies among ENNDs. During the study period, there was one baby weighing less than $1 \mathrm{~kg}$ at birth that did not survive resulting in $100 \%$ mortality. In the group with birth weight from $1 \mathrm{~kg}$ to less than $1.5 \mathrm{~kg}$, out of 5 babies, 3 babies died resulting in $60 \%$ neonatal mortality. Babies with birth weight of more than $1.5 \mathrm{~kg}$ but less than $2.5 \mathrm{~kg}$ had early neonatal mortality of $2.2 \%$ and those babies with birth weight more than 2.5 $\mathrm{kg}$ had only $0.2 \%$ mortality (Table 3 and fig 1 ). $60 \%$ of the ENNDs occurred in the gestational age group of 28- 36 weeks. $60 \%$ of ENNDs occurred within 24 hours of birth. Among the maternal characteristics, $80 \%$ of the mothers of early neonatal deaths were aged between $20-35$ years. $50 \%$ of the mothers were primi gravida .Out of total births in the hospital; $29.7 \%$ of the mothers had delivered their babies by caesarean section while out of early neonatal deaths, $50 \%$ of the mothers were delivered by caesarean section (Table 1 and table 2). According to Wiggleworth's classification, 10\% of early neonatal deaths were in Group II, $60 \%$ in Group III, $20 \%$ in Group IV and 10\% in Group V (Table 4).

Table 1: Deliveries and Early Neonatal Deaths in 2 Year (November 2003 to October 2005 )

\begin{tabular}{|l|r|}
\hline Total no. of births & 1517 \\
\hline $\begin{array}{l}\text { Total no. of still births and total still birth } \\
\text { rate }\end{array}$ & $22(14.5)$ \\
\hline $\begin{array}{l}\text { Total no. of still births and rate (excluding } \\
<1 \mathrm{~kg})\end{array}$ & $20(13.4)$ \\
\hline Total no. of ENND and Total ENND rate & $10(6.7)$ \\
\hline $\begin{array}{l}\text { Total no. of ENND and rate (excluding }< \\
1 \mathrm{~kg})\end{array}$ & $9(6.1)$ \\
\hline PMR & $\mathbf{1 9 . 1}$ \\
\hline Extended PMR & $\mathbf{2 1 . 1}$ \\
\hline Caesarian section out of total births & $451(29.7 \%)$ \\
\hline
\end{tabular}

Table 2: Types of delivery of Early Neonatal deaths

\begin{tabular}{|l|c|c|c|c|}
\hline Normal delivery & 2 & 20 & 16 & 50 \\
\hline Caesarean section & 5 & 50 & 10 & 31.3 \\
\hline Breech delivery & 0 & 0 & 3 & 9.4 \\
\hline Twin delivery & 1 & 10 & 1 & 3.1 \\
\hline Premature delivery & 2 & 20 & 2 & 6.2 \\
\hline Total & $\mathbf{1 0}$ & $\mathbf{1 0 0}$ & $\mathbf{3 2}$ & $\mathbf{1 0 0}$ \\
\hline
\end{tabular}

Table 3: Early Neonatal deaths according to weight

\begin{tabular}{|c|c|c|c|}
\hline Weight & Total live births & \multicolumn{2}{|c|}{ Early Neonatal Death } \\
\hline & No. & No & $\%$ \\
\hline$<1 \mathrm{~kg}$ & 1 & 1 & 100.0 \\
\hline $1-<1.5 \mathrm{~kg}$ & 5 & 3 & 60.0 \\
\hline $1.5-<2.5 \mathrm{~kg}$ & 134 & 3 & 2.2 \\
\hline$>2.5 \mathrm{~kg}$ & 1359 & 3 & 0.2 \\
\hline Total & 1499 & 10 & \\
\hline
\end{tabular}

Table 4: Early Neonatal Death Analysis by Wigglesworth's classification

\begin{tabular}{|l|c|c|}
\hline Wiggleworth's classification & ENND & \\
\hline & No. & \% \\
\hline Group I & 0 & 0 \\
\hline Group II & 1 & 10 \\
\hline Group III & 6 & 60 \\
\hline Group IV & 2 & 20 \\
\hline Group V & 1 & 10 \\
\hline Total & $\mathbf{1 0}$ & $\mathbf{1 0 0}$ \\
\hline
\end{tabular}

Fig 1: Distribution of Early neonatal death according to weight

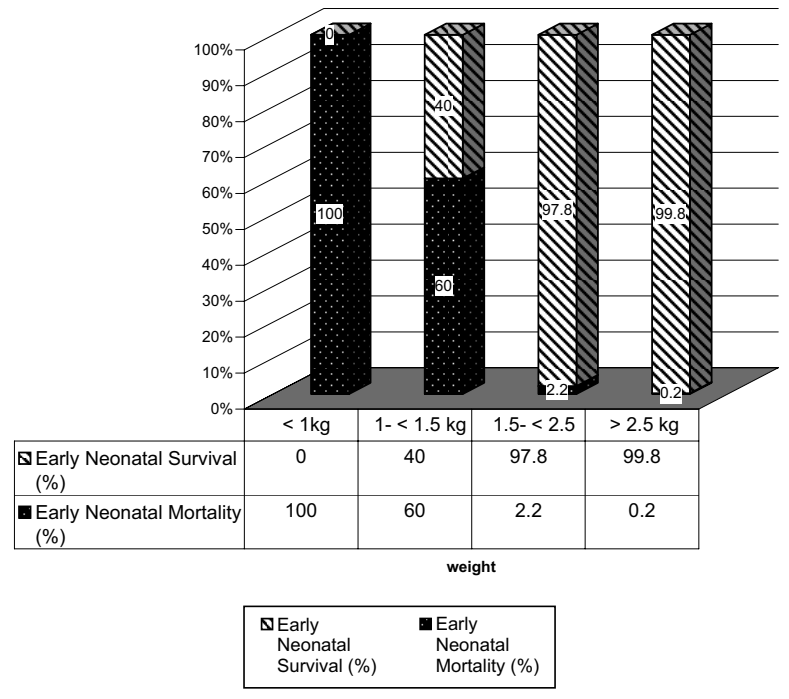


Fig 2: Distribution of early neonatal deaths by cause

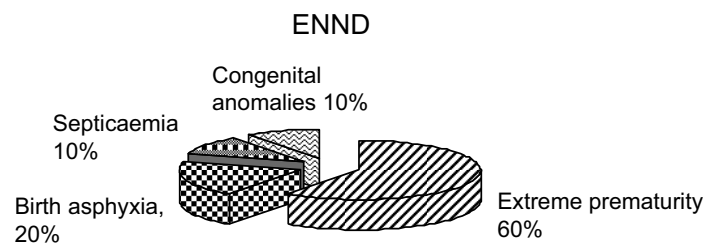

\section{Discussion}

It is estimated that around 30,000 newborns die each year in Nepal. Out of this, about 2/3rd of them die in the first week of life (early neonatal death) and 2/3rd of these early neonatal deaths occur in the first 24 hours of life. Nepal has a high Infant Mortality Rate (IMR) of 64 per 1000 live births and Neonatal Mortality rate (NMR) of 38.6 per 1000 live births ${ }^{4}$. NMR has fallen from 54.2 per 1000 live births in 1991 to the present 38.6 per 1000 live births in 2001 but the share of NMR in IMR has increased from $40 \%$ to $60 \%$ in the same period ${ }^{2}$.

The ENND rate at KMCTH is fairly low. The comparison of the early neonatal death rate at KMCTH, Maternity Hospital, Tribhuwan University Teaching Hospital (TUTH) and Nepal Medical College Teaching Hospital (NMCTH) is shown in Table 5. While the most important cause of ENND at Maternity Hospital was birth asphyxia, it was neonatal septicaemia in TUTH. The commonest cause of ENND at $\mathrm{KMCTH}$ and NMCTH is extreme prematurity which is very difficult to prevent and requires more intensive care than what is being done at present. The table also shows that $\mathrm{KMCTH}$ has a very low early neonatal death rate as compared to the major hospitals of Nepal except NMCTH. The factors that have contributed to a low ENND rate were mainly due to good antenatal care and care during delivery as there was almost $100 \%$ antenatal check up during pregnancy and each delivery were attended by medical personnel from the Departments of Pediatrics and of Obstetrics and Gynaecology besides labour room nurses. There was also good monitoring during labour as partograph was used during labour and quick interventions were undertaken whenever there was evidence of any problem. It is also important to note that majority of mothers who delivered at $\mathrm{KMCTH}$ were from medium to high socio-economic strata from Kathmandu area.

Table 6 compares the causes of early neonatal death of KMCTH with Maternity Hospital. The causes of neonatal death at the Maternity Hospital are similar to that of WHO data of 2001 which has shown that birth asphyxia and sepsis were the leading causes of neonatal mortality. Since majority of sepsis and birth asphyxia are preventable and treatable, neonatal mortality can be greatly reduced by proper interventions in time. But extreme prematurity is the leading cause of neonatal mortality in KMCTH which is very difficult to prevent and manage.

All neonates including high risk neonates were managed by locally made low cost equipments like Resuscitaire, Warm cot, Phototherapy unit, oxygen hood etc. These equipments are cheap, easy to use and maintain ${ }^{7}$. Use of such equipments drastically cuts the cost of newborn care in hospitals.

Each neonatal mortality case was discussed in detail within 24-48 hours after death to identify any preventable factor and take necessary actions. This audit has helped a lot in bringing awareness among doctors and nurses regarding preventable factors related to early neonatal deaths and providing better care for the neonates and mothers in the hospital.

Good antenatal care, good intrapartum care including use of partograph and timely intervention whenever any problem was detected were important factors related to good neonatal outcome. Low cost special care baby unit using locally made low cost equipment has been found to be adequate in managing most of the sick neonates. Extremely premature babies however require more intensive care needing ventilatory support and parenteral nutrition. However such intensive care is required for only a very small proportion of very low birth weight and extremely low birth weight babies (6 babies out of 1499 total live births). Therefore bringing awareness among women regarding importance of antenatal care and providing good antenatal and intrapartum care including use of partographs and provision of a low cost special care baby unit ${ }^{7}$ in all the district and zonal hospitals of the country would help in reducing the present high neonatal mortality to a great extent.

Table 5: Comparison of KMCTH with major hospitals

\begin{tabular}{|l|c|c|c|c|}
\hline & $\begin{array}{c}\text { KMCTH } \\
(2003-2005)\end{array}$ & $\begin{array}{c}\text { Maternity } \\
\text { Hospital }^{5} \\
(2005)\end{array}$ & $\begin{array}{c}\text { TUTH } \\
(2005)\end{array}$ & $\begin{array}{c}\mathrm{NMCTH}^{6} \\
(2003)\end{array}$ \\
\hline $\begin{array}{l}\text { ENND rate } \\
\text { (per 1000 live } \\
\text { births) }\end{array}$ & 6.7 & 15.3 & 12.5 & 4.7 \\
\hline
\end{tabular}

Table 6: Comparison of causes of neonatal death

\begin{tabular}{|l|l|c|c|}
\hline Rank & $\begin{array}{l}\text { Causes of Neonatal } \\
\text { Death }\end{array}$ & $\begin{array}{c}\text { KMC } \\
\mathbf{( 2 0 0 3 - 2 0 0 5 )}\end{array}$ & $\begin{array}{c}\text { Maternity } \\
\text { Hospital }^{5} \mathbf{( 2 0 0 5 )}\end{array}$ \\
\hline 1. & Extreme prematurity & $60 \%$ & $11.2 \%$ \\
\hline 2. & Birth asphyxia & $20 \%$ & $25.2 \%$ \\
\hline 3. & Sepsis & $10 \%$ & $20.87 \%$ \\
\hline 4. & Congenital anomalies & $10 \%$ & $11.02 \%$ \\
\hline 5. & $\begin{array}{l}\text { Respiratory Distress } \\
\text { Syndrome }\end{array}$ & & $15.8 \%$ \\
\hline 6. & Meconium Aspiration & & $6.3 \%$ \\
\hline 7. & Hypothermia & & $2.8 \%$ \\
\hline 8. & $\begin{array}{l}\text { Pulmonary } \\
\text { Hemorrhage }\end{array}$ & & $2 \%$ \\
\hline 9. & Others & & $4.3 \%$ \\
\hline
\end{tabular}




\section{Acknowledgements}

We thank the entire staff of the Department of Pediatrics and Department of Obstetrics and Gynaecology, KMCTH for their help and support. We also thank Mother and Infant Research Activities (MIRA) for providing support for this study.

\section{References}

1. Saving Newborn Lives. State of the world's newborns. Washington, DC: Save the Children, 2001.

2. Lawn E J, Cousens S, Zupan J. 4 Million Deaths: When? Where? Why; Lancet Neonatal Survival March 2005; 917.

3. Child Health Division, Department of Health Services, Ministry of Health. Newborn Health. In: The Child Health Profile of Nepal 2003. Kathmandu 2003; 12, 57.
4. Ministry of Health $(\mathrm{MoH})$, Annual Report. Department of Health Services 1995/ 1996, 1999/2000. Ministry of Health, Kathmandu, Nepal 1996, 2001.

5. Aryal D.R, Satyal I, Malla K .Perinatal Mortality At Maternity Hospital, Kathmandu 2061: Prospective Study. PESCON-5 Souvenir 2005:15-22.

6. Dali S M, Tuladhar H, Pradhan P, et al .Perinatal Death Audit : Retrospective Study. JNMA 2003; 42, 383-386

7. Manandhar D S and Costello A M de L. A Low-Cost Special Care Baby Unit At The Maternity Hospital In Nepal. Post-graduate Doctor Middle East 18(10): 362368. 